University of South Carolina

Scholar Commons

\title{
Nodal humor in comic narrative: a semantic analysis of two stories by Twain and Wodehouse
}

Christopher Holcomb

University of South Carolina - Columbia

Follow this and additional works at: https://scholarcommons.sc.edu/engl_facpub

Part of the English Language and Literature Commons

\section{Publication Info}

Humor: International Journal of Humor Research, Volume 5, Issue 3, 1992, pages 233-250.

Holcomb C. (1992). Nodal humor in comic narrative: a semantic analysis of two stories by Twain and

Wodehouse. Humor: International Journal of Humor and Research, 5(3), 233-250. DOI: 10.1515/

humr.1992.5.3.233

(c) 1992 Walter de Gruyter.

This Article is brought to you by the English Language and Literatures, Department of at Scholar Commons. It has been accepted for inclusion in Faculty Publications by an authorized administrator of Scholar Commons. For more information, please contact digres@mailbox.sc.edu. 


\section{Nodal humor in comic narrative: a semantic analysis of two stories by Twain and Wodehouse}

CHRISTOPHER HOLCOMB

\section{Abstract}

This paper shows that a semantic theory of humor offers, despite assertions to the contrary, an adequate description of how particular instances of humor are linked to the narrative in which they appear. After Victor Raskin's script-based semantic theory of humor is summarized, and adopted as the starting point of the analysis in this paper, the humor in two short stories is described in terms of their semantic properties. In this paper, humor is said to reside not simply in jokes but in joke-like constructions, for which the term "nodal points of humor" is used. These nodes can be identified by the presence of a semantic script opposition which is evoked, either explicitly or implicitly. Moreover, the scripts that characterize a node as humorous are the same as those that make the nodes coherent with the rest of the narrative. In the last section of this paper, generalizations are made about the pattern of script activation and reactivation in both stories.

Imprecision and an inability to integrate humor into a larger framework plague attempts made in the past to explicate comic narratives. Jerry Palmer, in his article "Theory of comic narrative: semantic and pragmatic elements" (1988), correctly identifies the two prevalent types of theories about comic narrative and their failures. The first uses traditional categories of literary analysis, such as character, plot, and genre, but fails to account precisely for the formal, especially the linguistic, features of comic narrative. For this reason, the first type cannot explain why a particular passage of discourse elicits a humorous response. The second theory, which concentrates upon the semantic properties of humor, treats the comic narrative as a structure embedded with a series of jokes (Palmer 1988: 111). Although semantic theories come closer to explaining the why 
of humor, they cannot, in Palmer's account, explain "the manner in which jokes and narrative are articulated together" (Palmer 1988: 114). This statement, one may suspect, was made before fully investigating the potential scope of existing theories because semantic analysis can show how instances of humor are tied to the larger narrative structure.

However, before semantic analysis can do this, it must first abandon the assumption that every case of humor in comic stories can be analyzed as if it were a joke - that is, as if it were a discrete item capable of being isolated from its context and explicated in terms of its own linguistic features. For, although jokes may produce some of the humor found in short stories, most of the humor issues from joke-like constructions. These constructions are recognizably humorous in the context of the narrative, but, if lifted from their context, they fall flat as jokes. In The Language of Humor, Nash hints at this distinction in his discussion of "Anecdotal structure" (Nash 1985: 68). He analyzes an anecdote taken from Jerome K. Jerome's Three Men in a Boat and notes that certain sentences in it exhibit "the likeness of a joke" (Nash 1985: 68). These sentences are not meant to be passed on orally as jokes in their own right, although they contain joke-like features. Rather, the humor in these sentences is produced by a context in which pressures create humor. So, for these sentences to elicit humor, one would have to recount the entire anecdote. Similarly, the author of a narrative must create a context that allows a particular incident to be funny. This differs from the joke because the joke - given an appropriate social setting that sanctions it - comes equipped more or less with its own context. This distinction between jokes and joke-like constructions is crucial to a theory that explains how the comic elements of a short story cohere with the comic narrative.

Therefore, the use of the word joke as a blanket term is inadequate. It suggests that humor in narratives can be classified as context-independent entities. Instead, the humor in narratives resides mostly in what I call nodal points of humor. Nodal points of humor are locations in the narrative where humor is perceptibly more concentrated than in the immediately surrounding text. Although they can be isolated as funny instances in the story, the nodal points remain semantically tied to the entire narrative. The analyses of the two short stories in this paper offer a way to identify nodal points of humor and show how they are linked to the rest of the narrative.

The concept of nodal humor owes much to Raskin's script-based semantic theory. Semantic Mechanisms of Humor (1985) provides both a 
formal theory and a method of analysis that precisely identify and explain jokes. Moreover, it suggests a means by which nodes of humor can be "articulated" in the same breath as detailed accounts of the fostering narrative. Particularly important for the concept of nodal humor are Raskin's use of scripts and the requisite condition of script oppositeness in the explication of jokes. I will summarize briefly Raskin's semantic theory of humor because it is drawn upon extensively in explicating the humor in two sample text - Mark Twain's "Journalism in Tennessee" and P. G. Wodehouse's "Ukridge's accident syndicate." These stories were chosen because few would argue against their intention to be funny, and, therefore, it can safely be presumed that humor is present.

\section{Raskin's semantic theory of humor}

Raskin grounds his theory of humor on script-based semantics. A script is a cognitive structure evoked by a word or a series of words and represents a native speaker's conventional knowledge of "certain routines, standard procedures, basic situations, etc." (Raskin 1985: 81). For example, the statement "she is making a trip" explicitly evokes what may be labelled as a "trip" or "travel" script. This script is a well defined structure that contains general knowledge of and associations with travel. It includes such elements as time and place of departure, a means of transportation, a route and duration of motion, and a time and place of arrival. Because a script is a relatively complete unit of information, any one of its constituent elements may evoke the entire script. For instance, if presented with the statement "she came home," we would infer that she had been on some sort of trip because "arrival" is normally a component of the "travel" script. The semantic script is a powerful concept because it contains, in a highly abbreviated form, the relatively predictable, hence structured, associations that cluster around a word or series of words describing a state of affairs or a process. In addition, our store and use of scripts account for the ways in which we draw inferences from and comprehend discourse (see Raskin 1985: 85-92).

Using the concept of script, Raskin characterizes a text as "single-jokecarrying" if two requisite conditions are met (Raskin 1985: 99). First, the text must activate two distinct scripts both of which are compatible with the text of the joke. Second, the two activated scripts must, in some sense, be opposite. Raskin states that this scriptic opposition can usually be 
classified into three general types of "real" and "unreal" situations: "actual" versus "non-actual" situations; "normal" versus "abnormal" states of affairs; and "possible" versus "impossible" situations (Raskin 1985: 111). An element called the "semantic script-switch trigger" effects the change from one script to the other. The trigger is either an ambiguity or contradiction which is present, explicitly or implicitly, in the text (Raskin 1985: 114).

Raskin uses the following joke as an example to demonstrate his theory:

Who was that gentleman I saw you with last night?

That was no gentleman. That was a senator (Raskin 1985: 25).

The two scripts activated and set in opposition are "senators are gentlemen" and "senators are not gentlemen." This opposition contrasts a "normal" state of affairs with an "abnormal" one. We normally expect senators to be upstanding citizens and, hence, gentlemen; therefore, it is abnormal not to consider them gentlemen. It is the ambiguity in the word gentlemen which triggers the switch from the one script to the other, because a "gentleman" may refer either to a "man" or to a "man of quality" (Raskin 1985: 114).

Below, the analyses of the two short stories assume the validity of Raskin's theory. However, they extend its domain from a "single-jokecarrying" text to the text of an entire comic narrative. The analyses also assume that the stories are coherent enough to communicate their humor and to elicit a humorous response. The assumption of coherence suggests that the stories will reveal, in part, their own cohesiveness in terms of semantic relations within the text. The semantic features of the text are used to identify and characterize nodes of humor. A nodal point of humor will contain one or several script oppositions - oppositions that occur within the node itself or that involve an allusion to some other region in the narrative. By this extension, a semantic theory of humor can account for nodes of humor and, more important, can find a means of incorporating those instances into the whole of the narrative.

\section{Mark Twain: "Journalism in Tennessee"}

In Twain's “Journalism in Tennessee," a first person narrator tells about his first day of work on a newspaper. He comes to the South, on the 
advice of his physician, to "improve his health." He acquires a position on a local paper as associate editor which, by some bizarre act of reasoning, is to be part of his convalescence. Contrary to his intention to recover his health, he, on the first day, finds himself caught in the middle of a feud raging between his chief editor and newspapermen from rival papers. Apparently, the feud has lost its novelty for the editor because he seems unruffled by the occasional bullet whizzing through the window or the odd hand grenade coming down the stovepipe. Ignoring these distractions, the chief editor continues to try to inculcate in the narrator the vigorous and slanderous style on which the paper prides itself. The narrator, however, can hardly ignore these attacks because he, by his mere presence, becomes their principal object. In fact, he suffers through seven onslaughts and at least as many wounds before he resigns his position and seeks refuge in a hospital. The humor issues mainly from the unexpected and violent exchanges among members of a supposedly civilized and respectable profession, from the thwarting of the narrator's desire to recover his health, and from the understated manner in which the narrator relates his reactions to being wounded by bricks, bullets, hand-to-hand combat, and a stove door.

A script analysis of the story accounts for most of the humor and shows how its nodes of humor are linked semantically with the narrative. The first sentence activates several scripts that pervade the remainder of the story:

I was told by the physician that a Southern climate would improve my health, and so I went down to Tennessee, and got a berth on the Morning Glory and Johnson County War-Whoop as associate editor (Twain 1983: 27).

The phrase "improve my health" establishes a "convalescence" script, and the clause "I ... got a berth on the Morning Glory and Johnson County War-Whoop as associate editor" evokes a "work" script, or, more specifically, a "journalism" script. The "convalescence" script includes the idea of rest which seems opposed to the "work" script. However, these two scripts do not produce humor because there is no trigger which causes the reader to abandon the former script in favor of the latter. That is, the "work" script does not impose a radically different interpretation on the "convalescence" script and does not introduce a highly abnormal or impossible state of affairs, even though one might question the logical relationship between the two scripts. But the name of the newspaper is amusing because of the abnormal juxtaposition of "Morning Glory," 
with its peaceful associations, and "War-Whoop," with its significantly less pacific associations. This name also violates expectations regarding normal titles of newspapers; one may wonder what sort of journalism is practiced by the writing staff of this paper. The first sentence, then, sets in place both the "convalescence" script and the "journalism" script; it also casts suspicion on exactly what manner of journalism is involved.

After describing the chief editor, the narrator receives from him an assignment to write a series of news briefs. The narrator does so and then presents his manuscript to the editor for "acceptance, alteration, or destruction." The editor immediately and energetically points out that the manuscript violates the customary style of the paper. The chief editor then proceeds to rewrite the narrator's first submission, completely changing a relatively neutral and objective text into a slanted, abusive, and slanderous piece of journalistic prose. For example, the narrator's seemingly innocuous and acceptable phrasing "The editors of the Semi-Weekly Earthquake" becomes, under the vehement pen of the chief editor, "The inveterate liars of the Semi-Weekly Earthquake." A readily apparent opposition is formed in these alterations. The "abnormal" and savage style of the chief editor opposes the "normal" or conventional style of the narrator, which agrees with, and refers to, normal expectations of the "journalism" script evoked by the story's opening sentence.

While the chief editor is making these stylistic corrections, the first of the series of seven violent events occurs. Because all of these events are similar in content and constitute a script in themselves - hence, the general label "violent event" - and because they are presented by the narrator in a similar manner, they are recognized as distinct units of the story. The manner in which the narrator manipulates language and deploys scripts is discussed after they are all quoted.

1. While [the chief editor] was in the midst of his work, somebody shot at him through the open window, and marred the symmetry of my ear.

2. And [the chief editor] snatched a navy revolver from his belt and fired. Smith [the somebody, above] dropped. The shot spoiled Smith's aim, who was taking a second chance, and he crippled a stranger. It was me. Merely a finger shot off.

3. Just as [the chief editor] finished [his erasures] a hand-grenade came 
down the stove pipe, and the explosion shivered the stove into a thousand fragments. However, it did no further damage, except that a vagrant piece knocked a couple of my teeth out.

4. About this time a brick came through the window with a splintering crash, a gave me a considerable of a jolt [sic] in the back. I moved out of range - I began to feel in the way.

5. Both pistols [the editor's and the Colonel's] rang out their fierce clamor at the same instant. The chief lost a lock of hair, and the Colonel's bullet ended its career in the fleshy part of my thigh. ... They fired again. Both missed their men this time, but I got my share, a shot in the arm. At the third fire both gentlemen were wounded slightly, and I had my knuckle chipped. I then said, I believed I would go out and take a walk, as this was a private matter, and I had a delicacy about participating in it further.

6. [The chief leaves the narrator in charge of the newsroom and tells him that he should expect some visitors.] Gellespie had called and thrown me out the window. Jones arrived promptly, and when I got ready to do the cowhiding he took the job off my hands. In an encounter with a stranger, not in the bill of fare, I had lost my scalp. Another stranger, by the name of Thompson, left me a wreck and ruin of chaotic rags.

7. I was in the act of resigning my berth on the paper when the chief arrived, and with him a rabble of charmed and enthusiastic friends. Then ensued a scene of riot and carnage such as no human pen ... could describe. People were shot, probed, dismembered, blown up, thrown out the window ... [Afterwards, the chief editor said] "You'll like this place when you get used to it." [The narrator said] "I'll have to get you to excuse me; I think I might write to suit you after a while. ... But ... that sort of energy of expression has its inconveniences, and a man is liable to interruption.... The experiences are novel ... and entertaining too, after a fashion, but they are not judiciously distributed.

Even lifted from their contexts, these excerpts still retain much of their humor. However, these excerpts obviously are not jokes but joke-like 
constructions. And as joke-like constructions, they function as nodal points of humor. To what, then, do these nodal points owe their humorous properties? And how can a script analysis help to account for their humor and show how they are integral elements of the entire story?

Before discussing scripts, however, it is useful to examine how carefully the narrator manipulates both language and his spatial orientation to the events he describes. Each excerpt begins with a description of an event as if the narrator were observing the action from a relatively safe distance. For example, in the first two clauses of the first excerpt, the narrator seems to assume a perspective that allows him a panoramic view of both the chief editor at his work and the "somebody" shooting through the window. In the next clause, the implied perspective abruptly shifts, and the description focuses on the ear of the narrator, who unexpectedly finds himself in the midst of the action. The narrator uses similar techniques in the other excerpts. In the second of them, the narrator says that an unspecified "stranger" is crippled, leading us to believe that he is at a distance observing the event. Then he instantly identifies the stranger as himself. These sudden shifts in focus play against conventional knowledge and expectations of narrative techniques, and thus contribute to the humor.

Although these clever shifts in perspective contribute to the wit, the main thrusts of humor come from both local and more distant script oppositions. Each excerpt begins with a graphic account of a violent act. The forcefulness of expression is largely a product of the lexical selection: "snatched," "shivered the stove into a thousand fragments," "splintering crash," "fierce clamor," "riot and carnage," and "short, probed, dismembered, blown up, thrown out the window." The first portion of each excerpt activates a "violent event" script, which includes an agent, an instrument, and an object of the violence; and all of them are present in each excerpt. What immediately opposes this script is the calm manner with which the narrator, the object, expresses his reaction. Each excerpt ends with the narrator's extremely understated responses to the violence and his descriptions of the results of the violent event: for example, "marred the symmetry of my ear," "he crippled a stranger. It was me. Merely a finger shot off," and "a vagrant piece knocked a couple of my teeth out." This use of understatement creates a tension, or opposition, between form and content because the actual manner of expression seems inappropriate to the content expressed. In addition to the tension inherent in understatement, the trope itself functions as a script in this particular 
context. The narrator's understated descriptions of his injuries are, by themselves, nonviolent events that locally oppose the violent events. Because his reactions seem unexpected and abnormal in these circumstances, the excerpts embody the opposition of a "normal" or "expected" state of affairs to an "abnormal" or "unexpected" state of affairs.

But these local oppositions, which now can be recognized as nodes of humor, are tied semantically to other parts of the story from which they gain an additional dimension of humor. This extra dimension derives from script oppositions that are not mentioned explicitly in the quoted excerpts but must be retrieved from other parts of the text. At the beginning of the story, the narrator activates the "convalescence" script which accounts for his reasons for coming to Tennessee. Then, as the narrator receives his various wounds, the "violent event" script opposes the "convalescence" script. There is an incompatibility between the narrator's intention to improve his health and the injuries he suffers as a result of that intention. Therefore, information contained in the "convalescence" script is imported from the opening of the story to play against the "violent event" script.

Other script oppositions are interspersed throughout the narrative. Perhaps the best and the most obvious example that illustrates both local and more distant oppositions is the conversational exchange between the chief editor and his adversary, another member of the journalistic profession. This exchange assumes the appearance of politeness, while, at the same time, they sustain their mutual enmity with abusive epithets. When the adversary makes his entrance, he says to the chief,

"Sir, have I the honor of addressing the poltroon who edits this mangy sheet?"

"You have. Be seated, sir. Be careful of the chair, one of its legs is gone. I believe I have the honor of addressing the putrid liar, Colonel Blatherskite Tecumseh?"

"Right, sir. I have a little account to settle with you. If you are at leisure we will begin."

"I have an article on the "Encouraging Progress of the Moral and Intellectual Development in America' to finish, but there is no hurry. Begin."

Both pistols rang out ... (Twain 1983: 30).

Here, the script of "polite verbal exchange" opposes the scripts of "impolite verbal exchange" and, more humorously, "bullet exchange." These are local script oppositions. At another level, though, this episode alludes to the "journalism" script activated at the beginning of the story. This script represents the conventional knowledge attributed normally to 
the practices of members of the journalistic profession, a profession that is supposedly civilized.

From the preceding analysis, it can be said that two major script oppositions characterize the humor in this story. Both the "convalescence" script and understatement oppose the "violent event" script, and the "journalism" script opposes what may now be regarded as an "abnormal journalism" or, rather, "Tennessee journalism" script. In the beginning of the story, the "convalescence" and the "journalism" scripts are firmly established, and, once evoked, they become part of one's presumed knowledge. As the story unfolds, humor emerges as other scripts are activated and implicitly opposed by scripts which have already been activated. In the violent episodes, for example, the humor derives much of its force not just from the local oppositions found in the understated responses but also from the "convalescence" script that was activated in the story's opening sentence. This correspondence, between those scripts that were activated at the beginning of the story and the other scripts that are activated at nodal points, semantically connects these nodes to the rest of the narrative.

\section{P. G. Wodehouse: "Ukridge's accident syndicate"}

As in the Twain story, much of the humor in Wodehouse's "Ukridge's accident syndicate" issues from several major script oppositions. But, unlike Twain, whose plot is linear and richly beaded with nodal points of humor, Wodehouse, in this story, constructs a more complicated plot iced with epigrammatic humor. Nevertheless, most of the humor in "Ukridge's accident syndicate," like that in "Journalism in Tennessee," can be revealed through script-based analysis. Moreover, this analysis demonstrates how Wodehouse integrates isolated instances of epigrammatic humor into a larger narrative form.

Wodehouse's epigrammatic style of humor pervades the story, providing a relatively constant flow of wit. However, the epigrammatic quality of his prose sometimes condenses into more tightly wrought, more overtly funny epigrams. Yet his are not the sort of epigrams one might hear quoted by the resident wit at a cocktail party, such as, "Experience is the name everyone gives to their mistakes," which appears in Oscar Wilde's Lady Windermere's Fan (1988 [1893]: 61). In this example, a direct application of script analysis, without regard to its surrounding context, reveals 
the semantic mechanisms that produce the humor. First, the epigram evokes two scripts, "experience" and "mistakes." Second, both scripts are compatible with the text but opposite in a special sense. A simple negation of "knowledge" captures the sense of the opposition: one who has experience presumably has knowledge, while one who makes mistakes has no knowledge, or, at least, no knowledge with respect to the mistake made. Finally, because the word name possesses several meanings, it acts as the trigger that effects the switch from the first script to the second. In contrast to Wilde's epigram, Wodehouse often uses more contextdependent epigrammatic constructions, or pseudo-epigrams, that reside in, or constitute, nodal points of humor. And it is the inability to extract them from their context that suggests his pseudo-epigrams are integral elements of his comic narrative.

Wodehouse's farce involves both a framing narrative and an embedded story which are recounted by a narrating character. The story begins when the narrator and Stanley Featherstonehaugh Ukridge, a obvious rogue, pass a church where a wedding is in progress. Ukridge somehow divines the identity of the groom. It is Teddy Weeks, an aspiring actor and a former acquaintance of the two men, and the principal antagonist of the embedded story. This coincidental encounter with Weeks's wedding becomes the springboard for the central story. In this, Ukridge devises a scheme to get some easy money. Having learned that the weekly papers are awarding accident insurance to their subscribers, Ukridge forms a syndicate among his cronies and persuades them to pool their money in order to subscribe to as many as possible. The syndicate then chooses, by lot, one of its members to have an accident in order to collect the vast amounts of money in insurance returns. When an accident does befall and the chosen member receives the returns, the syndicate will then divide the money among themselves. Weeks is chosen as "the man of destiny," but, in the subsequent action, he seems to consciously avoid having an accident. Finally, the requisite accident occurs, and Weeks finds himself in the hospital, collecting all of the insurance money. However, as an effect of his injury, he suffers from a selective and convenient amnesia which allows him to remember everything except the agreement to split the profits. The syndicate cannot pressure Weeks into handing over the money without incriminating themselves in a "conspiracy to obtain money under false pretenses" (279). The narrative then returns, five years later, to the time and place of the opening narrative. When Weeks emerges from the church, he is struck between the eyes with a tomato thrown by 
a "dishevelled" bystander that Ukridge has hired, on the spot, to perform the deed. Ukridge and the narrator, feeling that justice has been done, stroll away "arm in arm" (Wodehouse 1960: 280).

This story does not divide as easily into humorous events as Twain's does. The humor, however, does gather into nodes which are identifiable in two major script oppositions. Because one of the chief concerns of Ukridge and the syndicate is money, humor often is derived from opposing a "money" to a "no money" script. And because the acquisition of money entails some sort of plan, even though that plan involves having an accident, humor also is derived from the opposition of a "plan" to an "accident" script. One corollary opposition, and a more abstract script, accompanies the "accident" script. An accident normally entails a "loss by injury" script. However, for the sake of producing humor, Wodehouse frequently opposes this expected entailment with an abnormal and unexpected one, the "gain by injury" script in which the recipient of the injury profits by it. A "fate" script, a more general and abstract version of the "accident" script, follows from the chance component of any accident. All of these scripts are activated at the beginning of the story and serve as an implicit semantic backdrop to which any explicitly reactivated script can be opposed. Once a script has been evoked and firmly established, it continues to resonate throughout the story. Therefore, to reactivate a script is to reactivate, implicitly and automatically, the opposing script, as well.

The "no money" and "plan" scripts are activated just after the shift to the embedded narrative:

It was at Barolini's Italian restaurant in Beak Street that Ukridge evolved his great scheme. Barolini's was a favorite resort of our little group of earnest strugglers in the days when the philanthropic restaurateurs of Soho used to supply four courses and coffee for a shilling and sixpence (Wodehouse 1960: 265-266).

The word scheme hints at the "plan" script which is more explicitly activated later in the story. The concern of the "earnest strugglers" about the price of meals evokes the "no money" script. A later passage tells of the financially unsuccessful careers of the "earnest strugglers" and establishes more firmly the "no money" script. Nothing in this passage is exceedingly funny, apart from an intermingling of understatement and overstatement. However, these passages are necessary because they equip the reader with those scripts upon which the later instances of humor depend. 
The "accident" script, which later opposes the "plan" script, is also activated in the beginning of the story. Its activation is accompanied by the "fate" script. The narrator prefaces Weeks's exposition of himself with "As usual, Teddy Weeks had collared the conversation, and was telling us once again how good he was and how hardly treated by a malignant fate." This first mention of "fate" anticipates the evocation of the "accident" script which occurs just after another character, Freddie Lunt, enters the restaurant. Although a regular member of the group, Lunt has been absent from their dinners for over a fortnight. When made to account for his "aloofness," Lunt responds:

"I had an accident ... fell off my bicycle and sprained my ankle."

"Tough luck," was our verdict.

"Oh, I don't know," said Freddie. "It wasn't bad fun getting a rest. And of course there was the fiver."

"What fiver?"

"I got a fiver from the Weekly Cyclist for getting my ankle sprained."

"You-what?" cried Ukridge, profoundly stirred - as ever - by a tale of easy money. "Do you mean to sit there and tell me that some dashed paper paid you five quid simply because you sprained your ankle. Pull yourself together, old horse. Things like that don't happen."

"It's quite true" (Wodehouse 1960: 267).

Lunt, in his first utterance, activates the "accident" script and its normal entailment, the "loss by injury" script. The subsequent verdict, "Tough luck," carries the "accident" script's other corollary, the "fate" script. Also, the "money" script is reactivated by the word "fiver." The "gain by injury" script is evoked weakly with "It wasn't bad fun getting a rest. And of course there was the fiver." The utterance, "I got a fiver ... for getting my ankle sprained," evokes explicitly the "gain by injury" script and implies the opposition of "loss by injury" to "gain by injury." The occurrence of these scripts more firmly establishes the main issues upon which later instances of humor depend. They reappear or are alluded to later in the story in nodes and, thus, become part of the necessary knowledge for interpreting and appreciating subsequent incidents of humor.

Lunt then explains to the group, "you pay a year's subscription and that entitles you to accident insurance." This information sets Ukridge's brain "whirling like a dynamo" and provides him with the impetus for concocting his "scheme." However, before the scheme comes to full 
fruition in the mind of Ukridge, the narrator interrupts the action with an epigrammatic digression:

Nowadays papers are paying as high as two thousand pounds for a genuine corpse and five pounds a week for a mere dislocated spine; but at that time [that is, the time of the syndicate's formation, not the time of the framing narrative] the idea was new and had its attractive appeal (Wodehouse 1960: 267).

The humor in this passage derives from allusions to scripts appearing earlier in the story. In fact, this passage illustrates how scripts can collide and combine simultaneously on different levels. It is clear from the previous activation of the "no money" script that the "earnest strugglers" are in dire straits. Therefore, the evocation of the "money" script by "two thousand pounds" and "five pounds" implies its opposite, the "no money" script. Thus, it acquires a special significance in light of the preceding discourse. On another level, the word money specifies the "gain" variable in the "gain by injury" script evoked by "two thousand pounds for a genuine corpse and five pounds ... for a mere dislocated spine" and echoed by "attractive appeal." This script, which alludes to its first evocation in Lunt's utterances quoted above, opposes the more expected consequences of an injury - consequences which belong to the "loss by injury" script, also quoted above. This opposition succeeds because injuries bring immediate losses and impairments and not, usually, monetary gain. Moreover, it seems a blatant breach of propriety to place a price on death or injury. At least four scripts, which have already been established, are present and set in various oppositions in this passage. It is the repeated correspondence among scripts with other regions of the text that not only links this passage to the story but also allows it to succeed as a nodal point of humor.

Next, Ukridge, after considering the possibilities of Lunt's disclosure, explicitly defines the "plan" script:

"Here's the scheme. We take out subscriptions for all these papers, then we draw lots, and the fellow who gets the fatal card or whatever it is goes out and breaks his leg and draws the loot, and we split it up between us and live on it in luxury" (Wodehouse 1960: 268).

Here the script activity is dense and elaborately interwoven. The word scheme reactivates the "plan" script, while "draw lots" and "fatal card" echo the "fate" script. The phrase, "breaks his leg," evokes the "accident" script with its entailment, the "loss by injury" script, which is immediately 
opposed by the "gain by injury" script evoked with "draws the loot." Furthermore, "breaks his leg," as a particular type of injury, gains additional significance when it is learned that Weeks will be the victim. Earlier in the story, the narrator states that Weeks is an aspiring actor. Therefore, to tell Weeks to "break a leg" alludes to his being an actor and to the same phrase used by actors to wish each other good luck with a performance. This, in essence, is simultaneously a wish for harm and a wish for success. Finally, "loot" and "luxury" conjure up the "money" script. However, the overarching script opposition is between the "accident" and "plan" scripts. In many cases, it is normal to have or compose a plan, and, in just as many cases, it is relatively normal to have an accident; but to plan to have accident is highly abnormal and hardly to be expected in everyday life.

The story continues with several events that reveal Weeks's fastidiousness in avoiding accidents. Then Ukridge, determined not to let fate thwart his plans, tries to "hurry matters on." He lets loose in Weeks's apartment a dog, reputed for its "flashing fangs." He hopes, of course, that the dog will bite Weeks and thus effect the first stage of his plan. However, the attempt miscarries. Weeks manages to escape by climbing on top of his wardrobe, and Victor Beamish, who happens by chance to be accompanying Weeks, is bitten instead. In this node the humor springs from the opposition between the "plan" and "accident" scripts; that is, Ukridge intervenes so that Weeks will have an accident, but this planned accident does not succeed.

This section of the story is also interspersed with pseudoepigrams. Ukridge says of Weeks, "Never trust a man who waves his hair." This facetious warning refers to the "corrugated hair" of Weeks. The narrator comments, "In a crippled world, it seemed, Teddy Weeks walked alone, whole and glowing with health" (note the local opposition between "crippled" and "health" and the long distance opposition with the "injury" scripts). When the narrator learns it was Beamish, and not Weeks, who was bitten, he says, "It seemed as if Fate was going out of its way to have sport with us." In this pseudoepigram, the comic force comes from the explicit reactivation of the "fate" script and its opposition to the "plan" script alluded to by "have sport with us." Finally, the narrator laments, "A dog-bitten Victor Beamish had no market value whatever." The "dog-bitten Victor Beamish" reevokes the "accident" script and its normal entailment, the "loss by injury" script. The phrase "no market value" refers to the "money" and the "gain by injury" scripts, 
both of which oppose the "accident" and "loss" scripts. All of these pseudoepigrams are linked semantically to other locations in the story. They are recognizable as nodes because they contain either local oppositions or oppositions between scripts activated earlier in the narrative.

Weeks finally has an accident. At a "keying-up dinner" designed to muster up his courage to have an accident, Weeks consumes, in the form of champagne, the remnants of the syndicate's funds. He gets drunk and, to the syndicate's surprise, tells them that he has no intention whatsoever of having an accident. Then, as the syndicate loses all hope and the party seems to be breaking up, Weeks, "stepping off the curb onto a banana skin, was instantly knocked ten feet by a passing truck." At this point, the opposition between the "accident" and the "plan" scripts, which had been established firmly by repeated activations, reverses itself; the "accident" and the "plan" scripts now cooperate, and Ukridge's scheme, by chance, succeeds. This twist of fate is actually a higher-ordered opposition. The reader expects the continual opposition between the "plan" and "accident" scripts, but that expectation is deflated and causes a new opposition between the reader's expectations and the actual events of the story.

After the accident, when Ukridge and the narrator visit Weeks in the hospital, they find that Weeks is suffering from selective amnesia. He remembers subscribing to the papers and is now enjoying his new found wealth, but he remembers nothing of the syndicate and the agreement to divide the returns. Here, the embedded story comes to an end, and the narrative returns, five years later, to the scene outside the church where Weeks's wedding is ending. Just as Weeks and his bride emerge from the church, a "juicy" tomato "well and truly aimed ... burst[s] like a shell full between Teddy Weeks's expressive eyes" (280). Ukridge and the narrator, with their faith in poetic justice renewed, make their exit.

The humor, as in Twain's story, comes from several script oppositions, most notably from the opposition of the "plan" to the "accident" script. By repeatedly activating, or alluding to, these and other major scripts, Wodehouse creates a comic narrative whose nodes of humor are inextricably tied to the rest of the narrative.

\section{Conclusion}

It may seem strange to bring together Mark Twain and P. G. Wodehouse, because Twain, the prototypical American humorist, storyteller, yarnspin- 
ner, seems farther than an ocean's breadth from the urbane, incurable, and durable Edwardian wit, Wodehouse. Yet this unusual juxtaposition forces to the surface a pattern of script deployment shared by both stories. At the beginning of each, several major scripts are evoked. These are held in suspension as the discourse proceeds and then appear in opposition at nodal points, those regions in the text where the humor seems especially concentrated. In the nodes, the mere mention of any element of an already established script sufficiently evokes the full script.

Furthermore, this ability to recognize scripts and their components transcends the particular styles and idiosyncrasies of two quite different authors. In Twain's story, each "violent event" contains a local opposition in which the violence of the event is set against the understated reaction of the injured narrator. The "violent event" also contains more distant oppositions when considered in relation to the "convalescence" and the "journalism" scripts. In Wodehouse's story, whose more involved plot and epigrammatic style contrast it with Twain's, several scripts - the "accident" and "plan" scripts, for example - are activated at the beginning of the story and then are richly interwoven and knotted into nodes throughout the remainder of the narrative.

The reader intuitively recognizes those locations in a comic narrative where the humor seems more concentrated and more poignant. A sudden laugh or quiet smile betrays their whereabouts. This intuition supports the claim that humor accumulates into nodes but says nothing about the formal characteristics of these nodes. However, Raskin's script-based analysis allows the reader to crack the nodes and give a rigorous account of their semantic constituents. Once the constituents are identified, it is then possible to trace the semantic links back to scripts evoked earlier. From these earlier scripts, the nodes gain their sustenance and vigor. In this way, the reader can see how the nodes of humor are linked semantically to the entire comic narrative.

The University of Texas at Austin

\section{References}

Nash, W. 1985

Palmer, J. The Language of Humor. London: Longmans.

1988

Theory of comic narrative: semantic and pragmatic elements. HUMOR: International Journal of Humor Research 1(2), 111-126. 


\section{C. Lolcomb}

\section{Rinkin, Victor}

1985 Semantic Mechanimus of Homor. Dordecht: Reidel.

Twain, Mark

1983

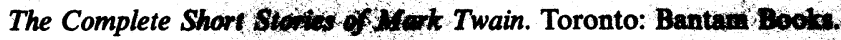

Wilde, Oscar

1988 [1893] Lady Windermere's Fan, In Lohr, John (ed.), The Plays of Osear Wilde.

New York: Vintage.

Wodehouse, P. G.

1960 The Most of P. G. Moddhouse. New York: Simon and Schuster. 